\title{
Avaliação das Ultrapassagens dos Padrões de Ozônio Troposférico no Estado de São Paulo de 2014 a 2019
}

\author{
Natasha Murgu Valdambrini ${ }^{1}$ (D) , Flávia Noronha Dutra Ribeiro ${ }^{1}$ \\ ${ }^{1}$ Programa de Pós-Graduação em Sustentabilidade, Escola de Artes, Ciências e Humanidades, \\ Universidade de São Paulo, São Paulo, SP, Brasil.
}

Recebido em: 9 de Outubro de 2021 - Aceito em: 16 de Novembro de 2021

\begin{abstract}
Resumo
Neste estudo foi feita uma análise utilizando os dados de monitoramento da qualidade do ar para estações com ultrapassagens do padrão de ozônio, visando caracterizar a distribuição espacial e variação temporal deste poluente, nas principais regiões do Estado de São Paulo entre os anos de 2014 a 2019. O ozônio é um poluente secundário e depende da presença de seus precursores na atmosfera, os óxidos de nitrogênio e os compostos orgânicos voláteis. A Região Metropolitana de São Paulo (RMSP) apresenta o maior número de ultrapassagens do Padrão de Qualidade do Ar (PQAr), principalmente devido à maior emissão dos precursores, um total de 875 ultrapassagens de 2014 a 2019 . O Interior apresenta 331 ultrapassagens e a Região Metropolitana da Baixada Santista (RMBS) 24 ultrapassagens no mesmo período. Os anos com mais ultrapassagens são 2014 e 2019 para a RMSP, no verão e na primavera, 2014 e 2017 para o Interior, principalmente na primavera, e 2014, 2015 e 2016 para a RMBS, principalmente no verão. Os picos de ultrapassagem estão associados a condições propícias para a formação do ozônio: baixa precipitação, baixa nebulosidade, alta temperatura e alta incidência de radiação solar. Uma possível alternativa sugere que diminuições nas emissões veiculares sejam consideradas.
\end{abstract}

Palavras-chave: ozônio troposférico, qualidade do ar, região metropolitana de São Paulo, Estado de São Paulo, região metropolitana da Baixada Santista.

\section{Assessment of Exceedances of Tropospheric Ozone Standards in São Paulo State from 2014 to 2019}

\begin{abstract}
In this study, an analysis was performed using the air quality monitoring data for stations with exceedances of the ozone, aiming to characterize the spatial distribution and temporal variation of this pollutant, in the main regions of the State of São Paulo between the years 2014 to 2019. Ozone is a secondary pollutant and depends on the presence of its precursors in the atmosphere: nitrogen oxides and volatile organic compounds. The Metropolitan Region of São Paulo (MRSP) presents the greatest number of the Air Quality Standard (AQS) exceedances, mainly due to a greater precursor emission, a total of 875 exceedances from 2014 to 2019. The countryside presents 331 exceedances and the Metropolitan Region of Baixada Santista (MRBS) presents 24 exceedances in the same period. The years with the most number of exceedances are 2014 and 2019 for the MRSP, in the summer and spring, 2014 and 2017 for the countryside, mainly during spring, and 2014, 2015, and 2016 for the MRBS, mainly during summer. The peaks of exceedances are associated with favorable conditions for ozone formation: low precipitation rates, low nebulosity, high temperatures, and high solar radiation incidence. A possible alternative suggests that decreases in vehicular emissions should be considered.
\end{abstract}

Keywords: tropospheric ozone, air quality, metropolitan region of São Paulo, Estado de São Paulo, metropolitan region of Baixada Santista.

Autor de correspondência: Natasha Murgu Valdambrini, natasha.valdambrini@usp.br. 


\section{Introdução}

Com área de aproximadamente $249.000 \mathrm{~km}^{2}$, o Estado de São Paulo, localizado na região sudeste, é o mais populoso entre os estados brasileiros, com 46,3 milhões de habitantes, $21,9 \%$ da população total do país, tendo a maior ocupação territorial, maior desenvolvimento econômico e maior frota automotiva. Como consequência, apresenta grande alteração na qualidade do ar (CETESB, 2020; IBGE, 2020). A poluição do ar representa hoje um dos maiores problemas de saúde pública afetando a saúde dos seres humanos, de outros animais e das plantas. Casos de doenças respiratórias e cardiovasculares são os mais relacionados à poluição atmosférica (Hystad et al., 2020) e crianças, adolescentes e idosos são os grupos mais vulneráveis aos efeitos dos poluentes (Martins et al., 2001; Braga et al., 2001; Schwartz, 2004; Martins et al., 2004).

$\mathrm{Na}$ parte inferior da atmosfera, chamada troposfera, o ozônio $\left(\mathrm{O}_{3}\right)$ é um dos maiores problemas globais da atualidade. $\mathrm{O} \mathrm{O}_{3}$ é um poluente secundário, ou seja, sua formação se deve a reações fotoquímicas entre seus precursores, os óxidos de nitrogênio $\left(\mathrm{NO}_{\mathrm{x}}\right)$ com os Compostos Orgânicos Voláteis (COVs), que são lançados na atmosfera tanto por fontes antropogênicas quanto por fontes biogênicas (Sharkey et al., 1993; Chiquetto et al., 2019).

$\mathrm{O}$ processo de formação do $\mathrm{O}_{3}$ é um processo complexo e não linear, pois depende das concentrações de seus precursores e de condições meteorológicas. Sua formação pode ocorrer em até duas horas após a emissão de seus precursores, que mesmo no processo de formação do $\mathrm{O}_{3}$ continuam sendo transportados a favor dos ventos, fazendo com que sejam encontradas altas concentrações de $\mathrm{O}_{3} \mathrm{em}$ regiões distantes do local de emissão de seus precursores (Chiquetto et al., 2019). Em locais denominados $\mathrm{NO}_{\mathrm{x}}$ limitantes, com abundância de COVs comparado ao $\mathrm{NO}_{\mathrm{x}}$, a diminuição de $\mathrm{NO}_{\mathrm{x}}$, levará a uma rápida diminuição da produção de $\mathrm{O}_{3}$, enquanto que em regiões em que a concentração de COVs não é muito maior que a concentração de $\mathrm{NO}_{\mathrm{x}}$, conhecidas como COVs limitantes, uma diminuição nas emissões de $\mathrm{NO}_{x}$, pode causar um aumento significativo nas concentrações de $\mathrm{O}_{3}$ (Martins et al., 2008; Orlando et al., 2010). Para a diminuição das concentrações de $\mathrm{O}_{3}$, a redução da emissão de seus precursores é uma alternativa, por isso é de fundamental importância o conhecimento quantitativo destes precursores, a fim de prever como possíveis mudanças nas concentrações destes, influenciarão na produção final de $\mathrm{O}_{3}$ (Orlando et al., 2010; Alvim et al., 2014; Martins et al., 2015; Alvim et al., 2016; Dominutti et al., 2016; Francisco et al., 2016; Alvim et al., 2018; Dominutti et al., 2020; Coelho et al., 2021).

Em áreas metropolitanas, as emissões veiculares são as principais responsáveis pela emissão de $\mathrm{NO}_{\mathrm{x}}$ e COVs, dependendo, principalmente, do tipo de combustível utilizado. O uso do etanol como combustível emite menores quantidades de $\mathrm{NO}_{\mathrm{x}}, \mathrm{COVs}$, hidrocarbonetos e material particulado, comparado à combustão da gasolina e do diesel. Em contrapartida, a combustão incompleta do etanol gera mais aldeído, mais especificamente, o formaldeído e acetaldeído, que possuem um papel importante na formação do $\mathrm{O}_{3}$ por serem bastante reativos (Grosjean et al., 1990; Corrêa et al., 2010; Nogueira et al., 2014; Salvo et al., 2014; Alvim et al., 2018). Vários estudos já foram realizados sobre o uso do etanol como principal combustível na Região Metropolitana de São Paulo (RMSP) e o impacto na qualidade do ar para $\mathrm{O}_{3}$ (Nogueira et al., 2014; Brito et al., 2015; Alvim et al., 2016; Dominutti et al., 2016; Nogueira et al., 2017; Brito et al., 2018; Alvim et al., 2018; Dominutti et al., 2020).

As maiores concentrações de $\mathrm{O}_{3}$ ocorrem no período que compreende as estações de primavera e verão no hemisfério sul, nos meses entre setembro a março, mas principalmente nos meses de setembro a outubro, pois apresentam condições propícias para a formação do $\mathrm{O}_{3}$, como alta incidência solar, devido à baixa nebulosidade, altas temperatura, acima de $20^{\circ} \mathrm{C}$, e pouca umidade, devido à ausência de chuvas neste período (Brasseur et al., 1999; CETESB, 2020). Picos de $\mathrm{O}_{3}$ são observados no período da tarde, cerca de 3 a 5 horas depois do pico matinal de emissão dos precursores e algumas horas após o máximo de radiação solar (Seinfield, 1989; Chiquetto et al., 2016).

Por ser um gás, é volátil e tem uma capacidade altamente oxidante, podendo contribuir significativamente para mudanças climáticas, uma vez que é o terceiro gás mais importante do efeito estufa, após o dióxido de carbono $\left(\mathrm{CO}_{2}\right)$ e o metano $\left(\mathrm{CH}_{4}\right)$, contribuindo com $8 \%$ para o aquecimento global (Amann et al., 2008; Programa Estadual de Mudanças Climáticas do Estado de São Paulo - PROCLIMA, 2021). Devido a suas características peculiares de formação, sua permanência na atmosfera pode variar de dias a meses, dependendo da estação do ano, no verão, por exemplo, quando as condições meteorológicas são mais propícias para a formação de $\mathrm{O}_{3}$, pode permanecer de cinco dias a algumas semanas, enquanto que no inverno, devido à baixa incidência solar neste período é de até 3 meses (Chiquetto, 2008).

Diversos estudos relacionando o $\mathrm{O}_{3}$ o como potencial causador da poluição atmosférica nas principais regiões do Estado de São Paulo são feitos com regularidade, principalmente na RMSP, uma vez que o Estado conta com uma ampla rede de monitoramento da qualidade do ar, o que facilita o estudo da região em relação à poluição atmosférica comparado aos demais estados do Brasil (Salvo et al., 2014; Carvalho et al., 2015; Martins et al., 2016; Andrade et al., 2017; Salvo et al., 2017; Gavidia-Calderón et al., 2018; Chiquetto et al., 2019; Schuch et al., 2019; Targino et al., 2019). Apesar desta disponibilidade de dados, não foram encontrados muitos estudos que façam a análise da poluição atmosférica por $\mathrm{O}_{3}$ 
levando em consideração o Estado de São Paulo como um todo. Boian et al. (2012) descreveram a interação do $\mathrm{O}_{3} \mathrm{e}$ seus precursores em duas regiões metropolitanas de São Paulo: a Região Metropolitana de São Paulo (RMSP) e a Região Metropolitana de Campinas (RMC). Chegando à conclusão de que as concentrações de $\mathrm{O}_{3}$ encontradas na RMC são provenientes das emissões locais e do transporte de $\mathrm{O}_{3}$ e precursores da RMSP, comprovando que existe impacto da megacidade nas vizinhanças e a importância das condições meteorológicas e topográficas no transporte de poluentes das fontes locais para regiões distantes. Francisco et al. (2016) avaliaram as concentrações de $\mathrm{O}_{3}$ e COVs em uma área urbana e rural da região de Araraquara, com influência de emissões da agroindústria de cana-de-açúcar, durante a safra e entressafra. Os resultados mostraram que apesar dos valores significativos de $\mathrm{O}_{3}$ na região, a contribuição dos precursores emitidos na agroindústria sucroalcooleira não desempenha papel determinante para o aumento dos níveis deste poluente. Carvalho et al. (2020), avaliaram o padrão e variabilidade das concentrações de $\mathrm{O}_{3}$ durante 18 anos nos finais de semana, em diferentes estações e locais em todo o Estado de São Paulo. Foi possível verificar que as variáveis estação do ano, dia da semana/fim de semana e estações de monitoramento estão inter-relacionadas, mostrando que as concentrações de máximas de $\mathrm{O}_{3}$ ocorrem aos finais de semana, independentemente da sazonalidade. As maiores concentrações de $\mathrm{O}_{3}$ encontradas foram durante a primavera, seguida pelo verão, devido à alta incidência solar e a variabilidade de cobertura de nuvens na maioria das estações de monitoramento. Squizzato et al. (2021) analisaram e compararam as concentrações de $\mathrm{O}_{3}, \mathrm{CO}_{2}$ e outros poluentes obtidas em uma estação de monitoramento móvel, situada na cidade de Botucatu, no interior do Estado de São Paulo, em relação às estações de monitoramento da RMSP. As concentrações de $\mathrm{O}_{3}$ não aumentaram durante o fim de semana em Botucatu, o que indica que o sistema atmosférico não é o mesmo que na zona central da RMSP (estação de Ibirapuera) e que provavelmente o $\mathrm{O}_{3}$ encontrado não é produzido localmente e sim transportado de outras regiões do entorno.

Neste contexto ainda, no âmbito mundial, podemos citar Gómez-Peláez et al. (2020) que fizeram uma revisão sobre as concentrações de dióxido de nitrogênio $\left(\mathrm{NO}_{2}\right)$, dióxido de enxofre $\left(\mathrm{SO}_{2}\right)$, material particulado (PM10 e PM2.5), monóxido de carbono (CO) e $\mathrm{O}_{3}$ a curto e longo prazo, considerando 11 áreas metropolitanas da América do Sul. Wang et al. (2017) fizeram uma análise das principais conclusões de artigos publicados sobre a poluição atmosférica por $\mathrm{O}_{3}$ e seus precursores em cidades da China, incluindo níveis de concentração, variação sazonal, influência da meteorologia na formação do $\mathrm{O}_{3}$, o transporte da poluição, efeitos do $\mathrm{O}_{3}$ na saúde e na vegetação, chegando à conclusão de que o transporte de poluentes inter-regiões ocorre de forma recorrente.
Uma análise preliminar das ultrapassagens de $\mathrm{O}_{3}$ no Estado mostrou que houve uma diminuição significativa dos totais de dias de ultrapassagens dos padrões estaduais de qualidade do ar para $\mathrm{O}_{3}$ em todo o Estado de São Paulo no período de 2014 a 2016. Um leve aumento ocorreu em 2017, retomando esta diminuição em 2018. Entretanto, em 2019, é possível verificar que houve um repentino aumento desproporcional destas ultrapassagens, deixando claro que o $\mathrm{O}_{3}$ é um poluente de difícil controle, pois não há uma tendência de longo prazo. Sendo assim, este estudo visa caracterizar a distribuição espacial do $\mathrm{O}_{3}$, considerando as principais regiões do Estado de São Paulo, com histórico de ultrapassagens dos padrões de qualidade do ar entre os anos de 2014 a 2019, baseado nos dados de monitoramento da qualidade do ar disponibilizados pela CETESB.

\section{Materiais e Métodos}

\subsection{Descrição da área de estudo}

O Estado de São Paulo abriga a Macrometrópole Paulista, com regiões densamente povoadas e com funções produtivas complementares. É formada pelas Regiões Metropolitanas de São Paulo (39 municípios), Campinas (20 municípios), Baixada Santista (9 municípios), Vale do Paraíba e Litoral Norte (39 municípios) e Sorocaba (27 municípios); as Aglomerações Urbanas de Piracicaba (23 municípios) e de Jundiaí (7 municípios); e a Unidade Regional de Bragantina (10 municípios). A Macrometrópole Paulista possui cerca de $75 \%$ da população do Estado, $75 \%$ da frota circulante e produz cerca de $82 \%$ do PIB estadual. A produção de etanol brasileira é feita em grande parte no Estado de São Paulo, cerca de $48 \%$ da produção nacional. A atividade de extração de etanol é extremamente geradora de poluentes atmosféricos, principalmente os gases do efeito estufa (CETESB, 2020), embora o cultivo de cana-de-açúcar também sequestre $\mathrm{CO}_{2}$ da atmosfera. Devido a este desenvolvimento, ocorrem alterações na qualidade do ar, com frequentes episódios de ultrapassagens dos níveis permitidos de poluição no Estado, destacando-se as regiões Metropolitanas de São Paulo e Campinas, o município de Cubatão e a região do Polo Cerâmico de Santa Gertrudes (CETESB, 2020).

Em 1970 a Companhia Ambiental do Estado de São Paulo (CETESB) iniciou o monitoramento da qualidade do ar em todo o Estado de São Paulo, através de estações manuais, que ainda hoje são utilizadas em 17 municípios e estações automáticas, iniciadas a partir de 1981, e que em 2019 totalizam 64 estações localizadas em 36 municípios, compreendendo uma população de aproximadamente 26 milhões de habitantes (CETESB, 2020). Sendo assim, o Estado de São Paulo possui uma ampla cobertura de rede de monitoramento da qualidade do ar, permitindo a inves- 
tigação e a criação de estratégias para controle de casos de poluição atmosférica.

Frequentes ultrapassagens do padrão de qualidade do ar (PQAr) estabelecido pela CETESB para $\mathrm{O}_{3}$ são medidas através das estações de monitoramento distribuídas por todo o Estado de São Paulo e divulgadas diariamente através da plataforma QUALAR de acesso livre. $\mathrm{O}$ valor considerado padrão para o $\mathrm{O}_{3}$ é de $140 \mu \mathrm{g} \cdot \mathrm{m}^{-3}$, chegando à última, das três etapas com um valor de $100 \mu \mathrm{g} . \mathrm{m}^{-3}$, referentes à média móvel de 8 horas e nível de atenção de $200 \mu \mathrm{g} . \mathrm{m}^{-3}$. Antes esta avaliação era feita considerando o Padrão Nacional de Qualidade do Ar, definido pela Resolução CONAMA no 3 de 1990. Apesar desta atualização, os valores de concentrações máximas do padrão e do nível de atenção ainda são muito elevados, comparados com as recomendações internacionais, dando margem à frequentes ultrapassagens dos padrões de qualidade do ar. Os padrões de qualidade do ar são considerados os níveis aceitáveis de cada poluente, baseado nos valores de concentração em relação ao tempo de exposição, de modo que os danos à população e vegetação exposta sejam minimizados.

A RMSP, é a região mais populosa do Estado, com 21,9 milhões de habitantes, o que corresponde a mais de $11 \%$ da população total do Brasil. Os primeiros estudos sobre a problemática da poluição atmosférica na RMSP datam da década de 70 (Andrade et al., 2015), desde então, diversos estudos abordando a problemática da poluição atmosférica por $\mathrm{O}_{3}$ na RMSP têm sido desenvolvidos.

Massambani et al. (1994), descreveram a natureza sazonal do $\mathrm{O}_{3}$ troposférico na RMSP, a relação entre seus precursores e parâmetros meteorológicos. Foram obtidas correlações entre o número total de horas de incidência solar com os valores médios de concentração horária de $\mathrm{O}_{3}$. Carvalho et al. (2015) fizeram uma análise das tendências de concentrações de cada poluente monitorado na RMSP durante catorze anos. Chegando à conclusão de que exceto para $\mathrm{o}_{3} \mathrm{O}_{3}$, houve uma diminuição nas concentrações dos poluentes, devido principalmente ao Programa de Emissões Veiculares (PROCONVE).

Sánchez-Ccoyllo et al. (2006a) descreveram o impacto da limitação dos precursores de $\mathrm{O}_{3}$ considerando três variáveis meteorológicas, concluindo que para uma redução efetiva nas concentrações de $\mathrm{O}_{3}$ é recomendado que as emissões de COVs sejam diminuídas e controladas através das taxas de reatividade de cada composto. Martins et al. (2008) concluíram que a formação de $\mathrm{O}_{3}$ na RMSP está mais sensível para variações de COVs do que para variações de $\mathrm{NO}_{\mathrm{x}}$. Este fato foi reafirmado por Orlando et al. (2010), que através de simulações indicaram que se houvesse uma redução de $30 \%$ nas emissões de COVs na RMSP, resultaria em uma redução total entre 30 e $42 \%$ nas concentrações de $\mathrm{O}_{3}$ e que o mesmo não se aplicaria ao reduzir as concentrações de $\mathrm{NO}_{\mathrm{x}}$.
Sánchez-Ccoyllo et al. (2006b) verificaram a influência que as trajetórias de massas de ar têm na dispersão de poluentes, como o $\mathrm{O}_{3}$, por fontes localizadas em áreas mais afastadas na RMSP. Santolaya et al. (2019) analisaram a variabilidade interanual das concentrações de $\mathrm{O}_{3}$ na RMSP, considerando somente os fatores meteorológicos na produção de $\mathrm{O}_{3}$. Isolando a contribuição de fatores químicos, foi possível observar que as concentrações de $\mathrm{O}_{3}$ não acompanharam a diminuição na concentração de $\mathrm{NO}_{\mathrm{x}}$, nem demonstraram uma linearidade durante o período de estudo.

Chiquetto et al. (2016) analisaram a variação temporal e espacial das concentrações de $\mathrm{O}_{3}$ na RMSP, considerando as características de uso do solo, avaliando o impacto da modificação do uso do solo pelo aumento da distância entre o ponto de monitoramento e as vias onde ocorre a emissão dos poluentes precursores, através de dados observados e simulações numéricas realizadas com modelo atmosférico. Através destas análises foi possível também o entendimento da influência da brisa marítima na dispersão $\mathrm{CO}$, monóxido de nitrogênio (NO) e $\mathrm{O}_{3}$. Franco et al. (2019) examinaram como diferentes tipos de superfície terrestre podem influenciar em uma adequada modelagem da qualidade do ar.

Chiquetto et al. (2019) demonstraram através de um evento de poluição extrema para $\mathrm{O}_{3}$ como a diferença dos limites nos padrões de qualidade do ar para $\mathrm{O}_{3}$ comparado aos padrões estabelecidos pela Organização Mundial da Saúde (OMS) influenciam no custo de saúde pública para os grupos vulneráveis durante o episódio.

A segunda maior região metropolitana do Estado de São Paulo, é a Região Metropolitana de Campinas (RMC), que fica na porção centro-leste do Estado, com população estimada de cerca de 3 milhões de habitantes e frota aproximada de 1,23 milhão de veículos. A região possui fácil acesso à importantes rodovias, proximidade com a RMSP e a presença de importantes centros de pesquisa, tornando a região em um dos maiores eixos de expansão industrial do interior do Estado, com alto grau de industrialização, de serviços e desenvolvimento agrícola, sendo influenciada tanto com emissões veiculares quanto com emissões industriais, o que causa um impacto significativo na qualidade do ar da região (D'Amelio et al., 2007; Ueda et al., 2011; da Cunha et al., 2017; CETESB, 2020; IBGE, 2020).

Nesta região, as principais cidades são Campinas, que é considerada a sede da região, é a cidade do interior, atrás da cidade de São Paulo, mais industrializada e urbanizada, tem uma concentração industrial que a deixa na terceira colocação do país e a sétima em relação à produção agrícola, com população de mais de um milhão de habitantes (Hogan et al., 2001), Paulínia, que apesar do seu tamanho, abriga um grande complexo industrial, principalmente petroquímico e a região do Polo Cerâmico de Santa Gertrudes, localizado nos municípios de Rio Claro, 
Santa Gertrudes, Cordeirópolis, Araras, Limeira, Ipeúna e Iracemápolis (Christofoletti et al., 2011). Na cidade de Paulínia, os ventos são preferencialmente de sudoeste, o que de acordo com de Tresmondi et al. (2004) contribui com o transporte de poluentes oriundos de Campinas e São Paulo (CETESB, 2020).

Cubatão é um município pertencente à região da Baixada Santista, onde grande parte da área total do município é recoberta por vegetação, está rodeado pela Serra do Mar, mas também possui áreas de planícies e manguezais. Em Cubatão está o maior Polo Industrial da América Latina, composto por indústrias dos setores petroquímico, siderúrgico, químico, de fertilizantes e logística. Nos anos de 1970 a 1980, ficou conhecida como uma das cidades mais poluídas do mundo, por ter tido sérios problemas de poluição atmosférica devido, principalmente à emissão desmedida de poluentes advindos das indústrias ali estabelecidas, da topografia da região e das condições meteorológicas desfavoráveis à dispersão de poluentes (CETESB, 2020).

Devido a esse histórico de problemas ambientais, diversos estudos sobre o impacto da poluição atmosférica na saúde da população da região foram desenvolvidos (Hofmeister, 1991; Jasinski, 2008; Guanabara, 2011; Jasinski et al., 2011; Nardocci et al., 2013). Outro tipo de metodologia muito utilizada nos estudos da região de Cubatão, pelo fácil acesso à vegetação nativa da região, é o uso de biomonitoramento, uma metodologia efetiva, fácil e econômica que avalia através do uso de plantas, o impacto dos poluentes sobre a vegetação que sofre com os efeitos da poluição atmosférica (Klumpp et al., 1994; Weitkamp, 1997; Klumpp et al., 2000; da Silva, 2012; CETESB, 2016; CETESB, 2020). Mesmo após a implementação do Plano de Prevenção de Episódios Agudos de Poluição do Ar em 1984, os padrões de qualidade do ar para alguns poluentes como o $\mathrm{O}_{3}$ e material particulado continuam sendo ultrapassados na região (CETESB, 2020).

A Tabela 1 apresenta os totais emitidos de $\mathrm{NO}_{\mathrm{x}}$ e COVs para a RMSP, Interior e Baixada Santista. Nota-se que a emissão da Baixada Santista é muito menor que a das outras regiões, mas também é a região com menor área de extensão. Já a RMSP apresenta a Tabela maior emissão de poluentes do Estado, mesmo tendo área menor que o Interior.

\subsection{Metodologia}

Atualmente a avaliação da qualidade do ar no Estado de São Paulo, é feita com base nos padrões estaduais de qualidade do ar estabelecidos pelo Decreto Estadual $\mathrm{n}^{\circ}$ 59.113 , de 23/04/2013, baseado nas diretrizes estabelecidas pela OMS, dividido em três etapas a serem seguidas gradualmente, de forma com que a exposição aos poluentes seja cada vez menor.

Para a análise realizada nesse trabalho, os dados de ultrapassagens do padrão de $\mathrm{O}_{3}$ foram levantados tanto dos relatórios anuais da CETESB quanto do sistema QUALAR, onde a CETESB disponibiliza acesso aos dados e análises utilizados para a confecção dos relatórios. As publicações da CETESB e o QUALAR também disponibilizam a classificação da representatividade espacial das estações e a vocação das mesmas, em respeito às fontes emissoras mais relevantes.

Para a análise meteorológica foram levantados dados e informações também dos relatórios da CETESB, com complementação dos relatórios da Estação Meteorológica do IAG. Também foram calculadas as médias mensais para as estações da RMSP, Interior e Baixada Santista da radiação solar global medida pelas estações da CETESB e disponíveis no sistema QUALAR.

A escolha das regiões de estudo foi baseada nos dados disponíveis pela CETESB. Na plataforma QUALAR verificou-se quais estações de monitoramento da CETESB disponibilizavam dados de $\mathrm{O}_{3}$ no Estado de São Paulo. Foram encontradas 56 estações e destas foram selecionadas as estações de monitoramento com ultrapassagens do padrão e do nível de atenção de qualidade do ar (PQAr): para a RMSP foram utilizadas 24 estações, no Interior do Estado foram 27 e 5 para a Baixada Santista, tanto com características vocacionais industriais, agropecuária e conservação.

\section{Resultados e Discussões}

A seguir os resultados serão apresentados em duas seções: a primeira é uma análise das condições meteorológicas e a segunda a análise das concentrações de $\mathrm{O}_{3} \mathrm{e}$ ultrapassagens do PQAr.

\subsection{Condições meteorológicas}

Os relatórios da CETESB consideram principalmente a precipitação, temperatura do ar, e a nebulosidade na

Tabela 1 - Emissão anual de poluentes para as regiões do Estado de São Paulo.

\begin{tabular}{lccccccccccccc}
\hline Região & $\mathrm{COV}$ & $\mathrm{NO}_{\mathrm{x}}$ & $\mathrm{COV}$ & $\mathrm{NO}$ & $\mathrm{COV}$ & $\mathrm{NO}_{\mathrm{x}}$ & $\mathrm{COV}$ & $\mathrm{NO}_{\mathrm{x}}$ & $\mathrm{COV}$ & $\mathrm{NO}_{\mathrm{x}}$ & $\mathrm{COV}$ & $\mathrm{NO}_{\mathrm{x}}$ \\
& \multicolumn{2}{c}{2014} & \multicolumn{2}{c}{2015} & \multicolumn{2}{c}{2016} & & 2017 & & 2018 & 2019 \\
\hline RMSP & 46 & 71,2 & 44,1 & 80,4 & 38,3 & 80,5 & 39,1 & 78,2 & 37,6 & 72,4 & 35 & 69,5 \\
Baixada Santista & 1,86 & 10 & 2,58 & 7,7 & 1,28 & 4,69 & 1,2 & 4,37 & 1,21 & 4,19 & 1,3 & 4,32 \\
Interior & 34,6 & 70,2 & 31,3 & 65,1 & 30,5 & 72,5 & 29,3 & 64,7 & 29,6 & 60,3 & 27,8 & 59,2 \\
\hline
\end{tabular}

Fonte: CETESB, 2015, 2016, 2017, 2018, 2019, 2020. 
análise de condições favoráveis à formação de altas concentrações de $\mathrm{O}_{3}$. Uma variável que pode ajudar a explicar as altas concentrações de $\mathrm{O}_{3}$ é a radiação solar incidente na superfície, uma vez que ela é importante na formação do $\mathrm{O}_{3}$ (Chiquetto, 2008). A Fig. 1 mostra as médias mensais de radiação solar global para: (a) RMSP, (b) Interior e (c) Baixada Santista medidas nas estações da CETESB, complementando as informações dos relatórios.

No ano de 2014, condições favoráveis para a formação de $\mathrm{O}_{3}$ aconteceram principalmente em janeiro, início de fevereiro e outubro, quando a presença de bloqueios atmosféricos inibiram a formação de nuvens e aumentaram a temperatura do ar e a incidência de radiação solar (Fig. 1). No restante dos meses as condições não foram muito diferentes das médias climatológicas ou foram menos favoráveis para a formação de $\mathrm{O}_{3}$, mas como um todo o ano teve índices pluviométricos abaixo do esperado (CETESB, 2015).

$\mathrm{O}$ ano de 2015 foi influenciado pelo fenômeno El Niño. Em janeiro, novamente observou-se a presença de bloqueios atmosféricos que propiciaram a formação de $\mathrm{O}_{3}$, mas as chuvas foram melhor distribuídas do que em 2014. Setembro e outubro foram meses com dias consecutivos sem precipitação e baixa nebulosidade e isso, aliado a temperaturas acima da média climatológica, propiciaram a formação de $\mathrm{O}_{3}$ e ultrapassagens do padrão (CETESB, 2016).

Em 2016 o El Niño não estava mais presente. De janeiro a março a precipitação foi acima da média. A temperatura também ultrapassou a média, criando condições favoráveis para a formação de $\mathrm{O}_{3}$, sobretudo na RMSP, onde aconteceu uma sequência de dias sem precipitação. Já o mês de abril apresentou bloqueio atmosférico e ausência de passagens de frentes frias, propiciando a formação de $\mathrm{O}_{3}$. Em agosto e setembro, as condições meteorológicas foram diferentes entre o Interior, com condições mais propícias à formação de $\mathrm{O}_{3}$ (Fig. 1b), e a RMSP e a Baixada Santista (Figs. 1a, c), com temperaturas mais amenas. Outubro e dezembro foram meses em que a formação de $\mathrm{O}_{3}$ foi favorecida, com altas temperaturas e chuvas abaixo da média (CETESB, 2017).

Em fevereiro e março de 2017 a precipitação foi abaixo da média climatológica, mas com poucos dias com condições propícias à formação de $\mathrm{O}_{3}$. Setembro e a primeira quinzena de outubro apresentaram a formação de bloqueios que inibiram a nebulosidade e a precipitação e aumentaram a temperatura do ar, caracterizando um período propício à formação de $\mathrm{O}_{3}$. Dezembro também apresentou altas temperaturas e condições favoráveis à formação de $\mathrm{O}_{3}$, mesmo com altos índices de pluviosidade. Além disso, o relatório da CETESB aponta para condições muito secas e muitas ocorrências de queimadas em setembro deste ano (CETESB, 2018).

O fenômeno La Niña atuou de janeiro a março de 2018. As altas temperaturas desse período, mesmo com
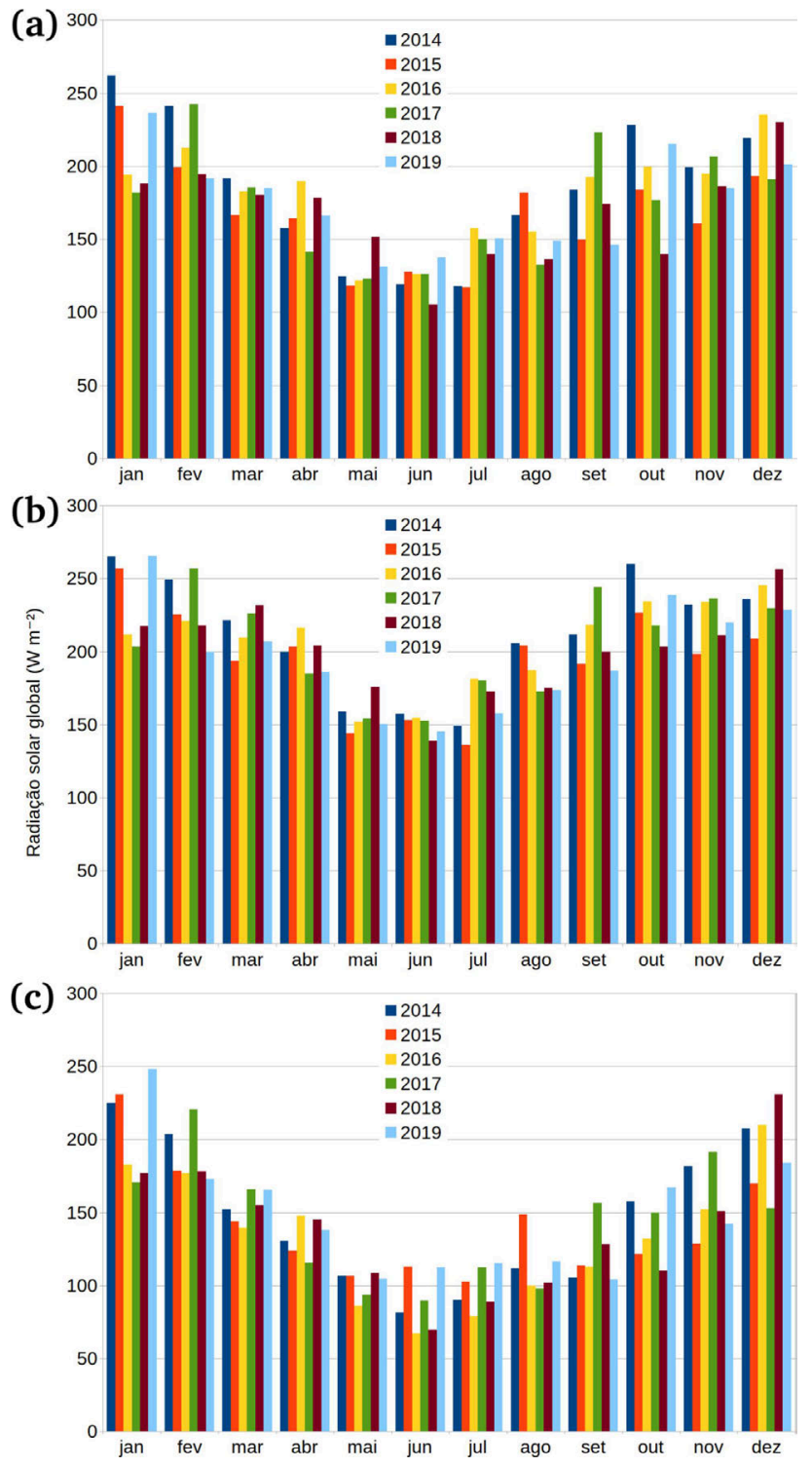

Figura 1 - Médias mensais da radiação solar incidente na superfície para (a) RMSP, (b) Interior e (c) Baixada Santista.

precipitação bem distribuída durante os meses, propiciaram a formação de $\mathrm{O}_{3}$, inclusive em dias de chuva. Apenas em dezembro as condições voltaram a ser favoráveis para formação de $\mathrm{O}_{3}$ em vários dias consecutivos, caracterizando 2018 como um ano desfavorável às altas concentrações desse poluente (CETESB, 2019).

Em janeiro de 2019 a precipitação foi abaixo da média em grande parte do Estado e observou-se temperaturas superiores à média de janeiro a março, com exceção da RMSP. As condições foram favoráveis a altas concentrações de $\mathrm{O}_{3}$. Altas temperaturas em alguns dias de abril possibilitaram a formação de $\mathrm{O}_{3}$ na RMSP. Em setembro as condições voltaram a ser favoráveis às altas concentrações de $\mathrm{O}_{3}$, com a presença de um anticiclone tropical inibindo a precipitação e mantendo altas tempe- 
raturas. Outubro apresentou temperaturas acima da média em todo o estado, com exceção de São José dos Campos. Novembro e dezembro também foram favoráveis às altas concentrações de $\mathrm{O}_{3}$ (CETESB, 2020).

\subsection{Concentrações de $\mathrm{O}_{3}$ e ultrapassagens do PQAr}

A Tabela 2 apresenta o total de ultrapassagens do padrão da qualidade do ar por região do Estado de São Paulo por ano. Observa-se que a RMSP registrou mais ultrapassagens em todos os anos que o Interior ou a Baixada Santista e é também a região que mais teve ultrapassagens do nível de atenção. Como há grande diferença na quantidade de estações de monitoramento entre as regiões, a Fig. 2 apresenta a média de ultrapassagens por estação de monitoramento, considerando apenas as estações que medem $\mathrm{O}_{3}$. Percebe-se que, mesmo dividindo-se o número de ultrapassagens pelo número de estações, a RMSP mantém uma maior frequência de ultrapassagens, enquanto a Baixada Santista apresenta a menor frequência.

Ainda com relação à distribuição espacial, verificase que a variação é grande, mesmo entre estações próximas (Fig. 3). Considerando a RMSP, que tem mais estações, verificamos um grande gradiente da concentração de $\mathrm{O}_{3}$ em algumas localidades, como por exemplo a estação IPEN-Cidade Universitária e a estação Pinheiros. Essas

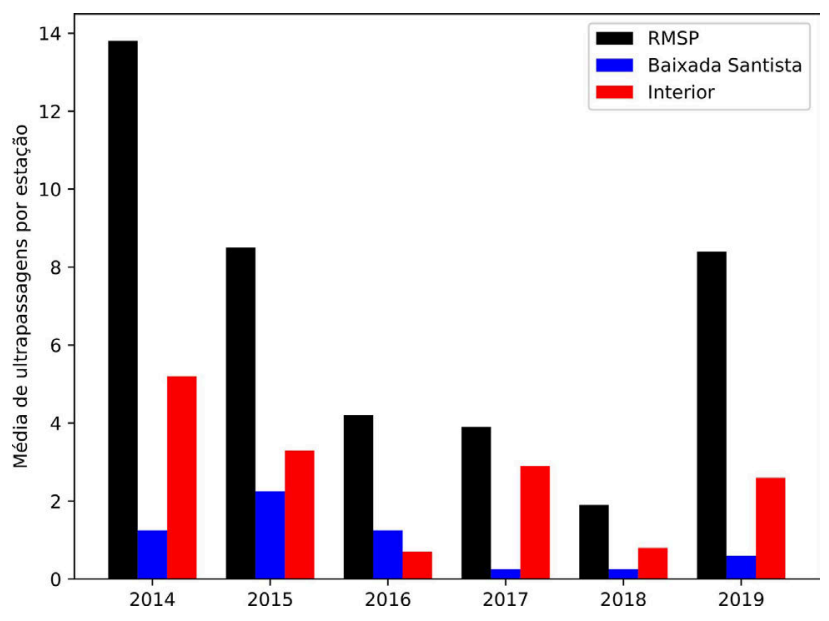

Figura 2 - Média de ultrapassagens por estação de monitoramento para as regiões RMSP, Baixada Santista e Interior, de 2014 a 2019. Fonte: Adaptado de CETESB $(2015,2020)$. diferenças remetem à característica das regiões e sua proximidade às fontes dos precursores de $\mathrm{O}_{3}$.

De acordo com a classificação da representatividade espacial das estações de monitoramento (CETESB, 2020), todas as estações da Baixada Santista são classificadas na escala de bairro, indicando uma área de $500 \mathrm{~m}$ até $4 \mathrm{~km}$ de representatividade. Isso parece indicar que o $\mathrm{O}_{3}$ realmente não apresenta concentrações muito altas onde é registrado. Já no Interior, as estações estão divididas entre urbanas e de bairro (14 e 13 estações respectivamente) e as estações urbanas, com representatividade entre 4 e $50 \mathrm{~km}$, apresentam uma média ligeiramente maior de ultrapassagens do padrão. Na RMSP há duas estações de microescala que medem $\mathrm{O}_{3}$ e são as que apresentam a menor média de ultrapassagens por estação em todo o período considerado. Dessa forma, embora as fontes veiculares sejam de grande importância para a formação do $\mathrm{O}_{3}$, a proximidade das fontes reduz a concentração desse poluente, como já discutido por Chiquetto et al. (2019). Em relação à vocação, todas as estações da RMSP e da Baixada Santista, com exceção apenas de São Sebastião que está numa área de conservação ambiental, têm vocação industrial, enquanto no Interior há 5 estações com vocação agropecuária e essas apresentam uma média menor de ultrapassagens por estação.

Nota-se também uma grande variação temporal: enquanto 2014 apresenta uma frequência $60 \%$ maior que os anos de 2015 e 2019 para a RMSP, o ano de 2018 apresenta a menor frequência para todas as regiões. A variação ano a ano também é similar entre as regiões, com exceção de 2015 para a Baixada Santista e de 2017 para o Interior. Esses padrões indicam que as condições meteorológicas de escala regional à global analisadas na seção 3.1 influenciaram as concentrações desse poluente.

A Fig. 4, que mostra as ultrapassagens do padrão de $\mathrm{O}_{3}$ para cada mês de 2014 a 2019, permite identificar períodos de maior ocorrência de altas concentrações de $\mathrm{O}_{3}$. Além do padrão sazonal já identificado por Carvalho et al. (2015), com os meses de outubro e janeiro os que apresentam mais dias com ultrapassagens, nota-se alguns períodos mais favoráveis à formação de $\mathrm{O}_{3}$. Os 3 maiores picos de ultrapassagens na RMSP foram outubro de 2014, janeiro de 2015 e outubro de 2019, meses em que bloqueios atmosféricos estavam em ação (Fig. 1a), diminuindo a nebulosidade e a umidade e aumentando a

Tabela 2 - Ultrapassagens totais anuais do padrão de qualidade do ar por região do Estado de São Paulo de 2014 a 2019. Os números entre colchetes são as ocorrências que também ultrapassaram o limite de atenção.

\begin{tabular}{lccccccc}
\hline Região & 2014 & 2015 & 2016 & 2017 & 2018 & 2019 & Total \\
\hline RMSP & $277[10]$ & $178[5]$ & $92[1]$ & 90 & 44 & $194[2]$ & 875 \\
Baixada Santista & 5 & 9 & 5 & 16 & 1 & 70 & 3 \\
Interior & $89[1]$ & 69 & $113[1]$ & 161 & 21 & 66 & 331 \\
Total & $371[11]$ & $256[5]$ & 66 & $263[2]$ & 1230 \\
\hline
\end{tabular}

Fonte: Adaptado de CETESB $(2015,2020)$. 


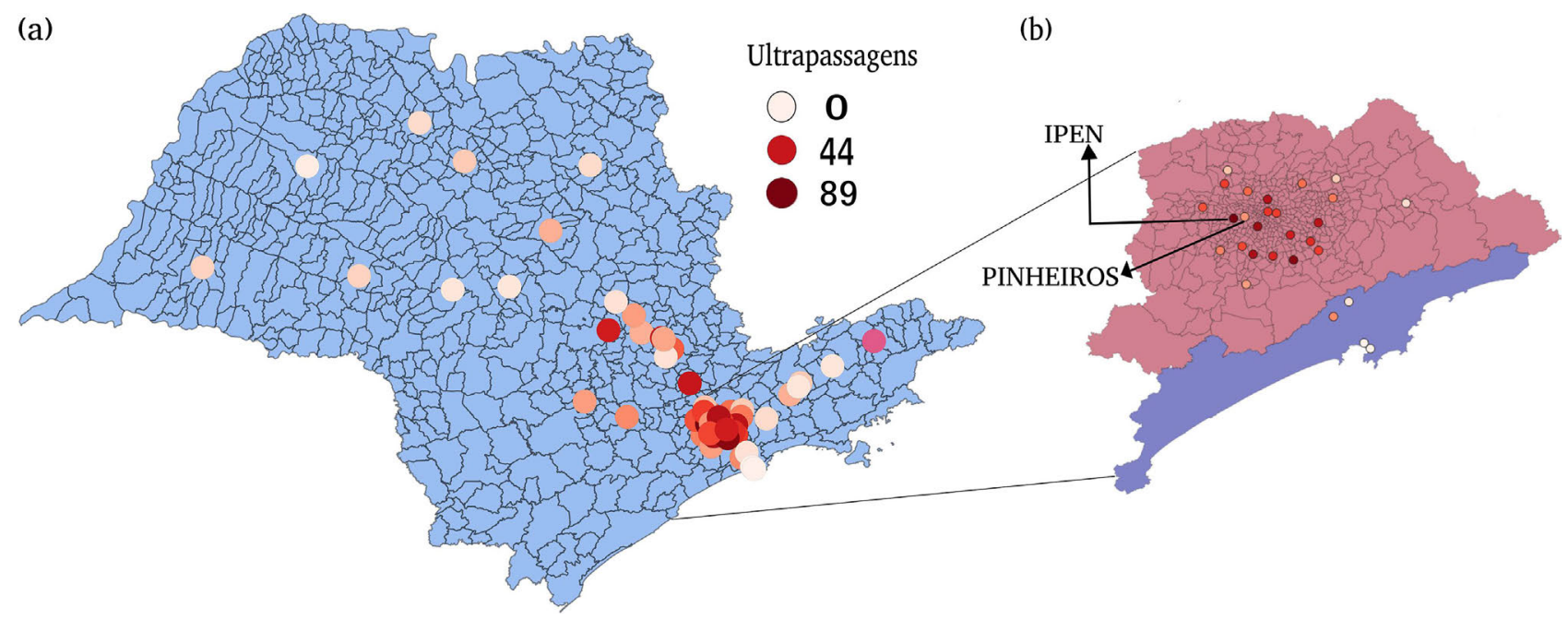

Figura 3 - Ultrapassagens totais do padrão para $\mathrm{O}_{3}$ de 2014 a 2019 por estação de monitoramento (a) no Estado de São Paulo e (b) com destaque para a RMSP (polígono) e para a Baixada Santista (polígono). Fonte: Adaptado de CETESB $(2015,2020)$.

radiação solar incidente e a temperatura do ar, de acordo com a avaliação da CETESB $(2015,2016$ e 2020) e da Estação Meteorológica do IAG (Fig. 4a). O ano de 2019, a exemplo de 2014, também apresentou diversos dias com ultrapassagens em janeiro e outubro, em situações de presença de anticiclones anômalos que inibiram nebulosidade. Em junho não houve dias com ultrapassagens em nenhum dos anos, uma vez que o inverno raramente apresenta condições para altas concentrações de $\mathrm{O}_{3}$. Para o Interior, os picos foram janeiro e outubro de 2014 e setembro de 2017. Embora o Interior tenha semelhanças com a RMSP, concentra suas ultrapassagens mais nos meses de primavera, excetuando-se janeiro de 2014 e 2015, e apresenta ultrapassagens em alguns meses em que a RMSP não teve ultrapassagens (Fig. 4b). Os meses de janeiro e fevereiro são os mais favoráveis para a formação de $\mathrm{O}_{3}$ na Baixada Santista (Fig. 4c). Olhando o Estado como um todo, janeiro de 2014 e 2015 e outubro de 2014 foram os eventos mais extremos.

A Fig. 5 apresenta as médias mensais da concentração de $\mathrm{O}_{3}$ para as 3 regiões: RMSP (Fig. 5a), Interior (Fig. 5b) e Baixada Santista (Fig. 5c). A comparação do número de ultrapassagens (Fig. 4) com as concentrações médias mensais para as regiões (Fig. 5) deve levar em conta que as ultrapassagens são calculadas com médias de 8 horas da concentração de $\mathrm{O}_{3}$. Dessa forma, as médias mensais podem ser mais altas em regiões em que a concentração não varia muito e que podem não trazer episódios de altas concentrações, enquanto outras regiões podem ter mais episódios de ultrapassagens enquanto a média mensal não é tão alta. Adicionalmente, as médias foram calculadas incluindo todas as estações da região, o que pode considerar estações com altas concentrações e estações com baixas concentrações, diminuindo a média mensal, enquanto as ultrapassagens são calculadas para cada estação. Percebe-se, portanto, que as concentrações no Interior (Fig. 5b) são às vezes maiores que na RMSP (Fig. 5a), embora a RMSP tenha um número maior de ultrapassagens.

Comparando-se as concentrações médias (Fig. 5) com a radiação média (Fig. 1), percebe-se uma clara influência das condições meteorológicas na concentração de $\mathrm{O}_{3}$, principalmente na sazonalidade e nos eventos propícios às ultrapassagens. Para a Baixada Santista (Figs. 1c e $5 \mathrm{c}$ ), percebe-se uma quantidade menor de radiação solar, provavelmente relacionada a uma maior nebulosidade por causa da umidade proveniente do mar marinho, indicando uma grande contribuição das condições meteorológicas nas concentrações desse poluente, além de menores emissões anuais (Tabela 1). No entanto, quando se compara o Interior com a RMSP (Figs. 1a-b e 5a-b), apenas as condições meteorológicas não podem explicar as diferenças observadas, pois a radiação solar é muitas vezes maior no Interior que na RMSP, indicando uma forte contribuição das fontes de emissão, conforme observado na Tabela 1.

Embora Carvalho et al. (2015) tenha apontado para uma tendência de redução da média anual do $\mathrm{O}_{3}$ para a RMSP de 1996 até o fim de 2009, quando olhamos para os dados mais recentes, essa tendência não é tão clara (Fig. 6), principalmente por causa de 2014 e 2019. A tendência das médias mensais das concentrações de $\mathrm{O}_{3}$ para o Estado (Fig. 6a) e para a RMSP (Fig. 6b) apresentam leve tendência de aumento. Esse comportamento pode indicar tanto influência das condições meteorológicas quanto a influência da redução de concentração de $\mathrm{NO}_{\mathrm{x}}$ e aumento do uso de etanol. Além disso, percebe-se que a Baixada Santista (Fig. 6d) não demonstra nenhuma tendência para as concentrações médias, nem de aumento e nem de diminuição, indicando a RMSP e o Interior (Fig. 6c) como responsáveis pela tendência do Estado. Ainda, o Interior 
(a)

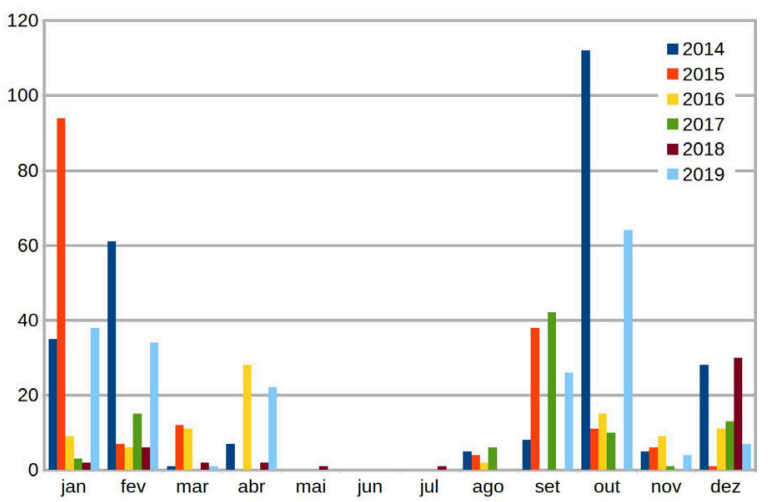

(b)

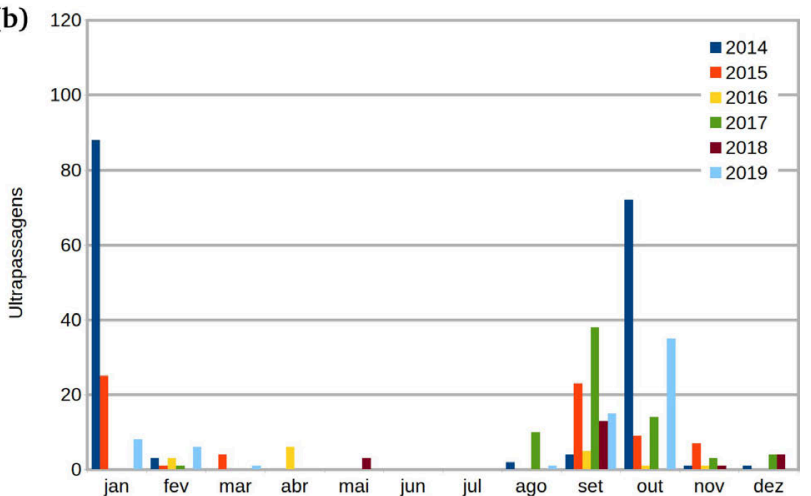

(c)

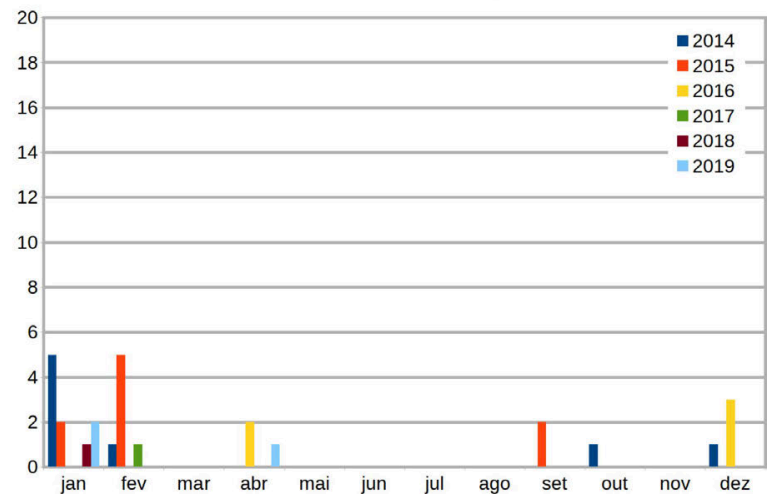

Figura 4 - Ultrapassagens do padrão de $\mathrm{O}_{3}$ por mês de 2014 a 2019 (a) na RMSP, (b) no Interior e (c) na Baixada Santista. Fonte: Adaptado de CETESB $(2015,2020)$.

apresenta uma taxa mensal $\left(0,067 \mu \mathrm{g} \cdot \mathrm{m}^{-3}\right.$ por mês $)$ maior que a média do Estado $\left(0,063 \mu \mathrm{g} \cdot \mathrm{m}^{-3}\right.$ por mês $)$, indicando que, embora o número de ultrapassagens seja maior na RMSP, é necessário que o poder público leve em consideração os padrões de emissão nas estações do Interior.

Uma observação importante que deve ser feita é a dificuldade para o cumprimento das metas de padrão da qualidade do ar para $\mathrm{O}_{3}$. Hoje o padrão do Estado é muito superior ao estabelecido pela OMS (média de 8 horas de $100 \mu \mathrm{g} \cdot \mathrm{m}^{-3}$ ) e temos diversas situações de risco à saúde da população, principalmente na RMSP. Se o limite da OMS fosse usado, o número de ultrapassagens do Estado passaria de 1230 para 11392, um aumento de mais de 8 vezes, com ultrapassagens em todas as regiões que registram esse (a)

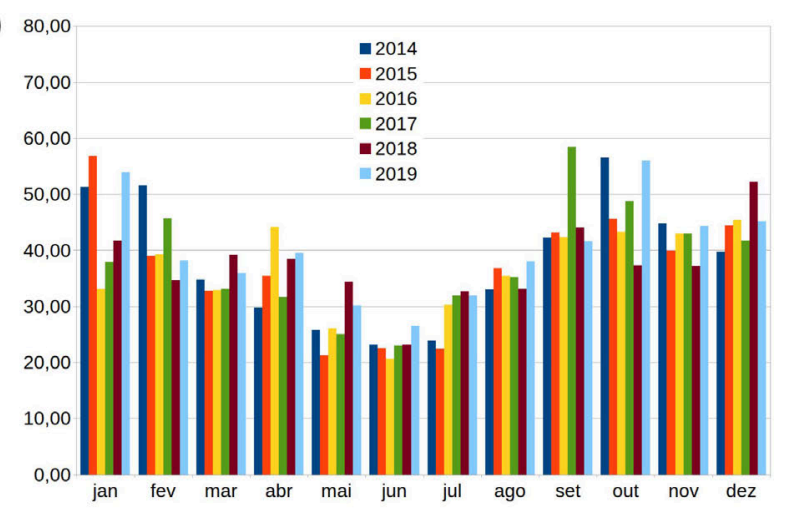

(b)
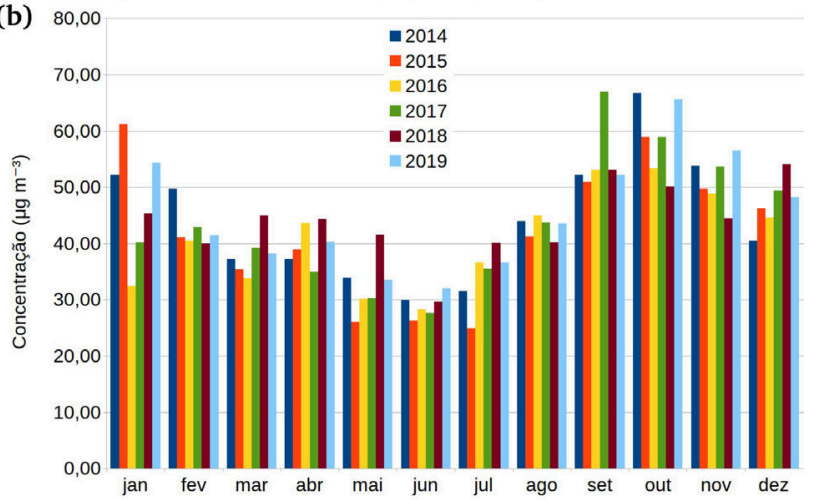

(c)
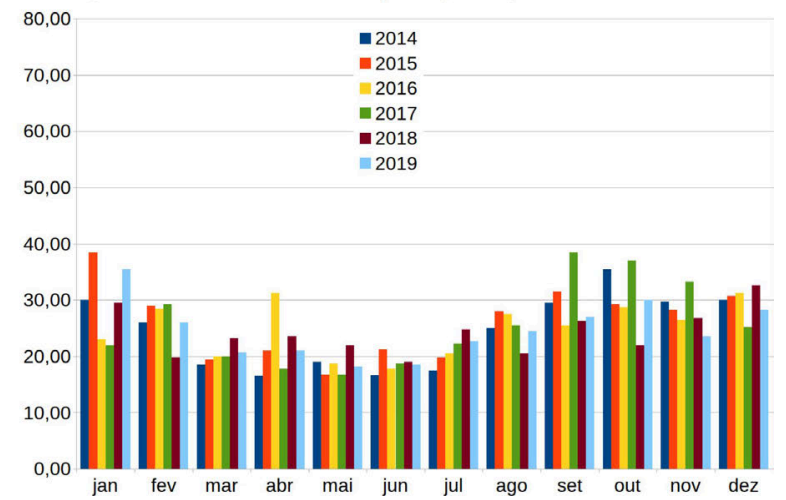

Figura 5 - Médias mensais da concentração de $\mathrm{O}_{3}$ para (a) RMSP, (b) Interior e (c) Baixada Santista. Fonte: Adaptado de CETESB (2015, 2020).

poluente. Dessa forma, verifica-se a necessidade de ações do poder público em direção a controlar a emissão dos precursores do $\mathrm{O}_{3}$ e a estabelecer medidas de adaptação e mitigação a situações de baixa qualidade do ar.

\section{Considerações Finais}

O presente trabalho realizou um estudo das ultrapassagens do padrão de qualidade do ar para o $\mathrm{O}_{3}$ em todas as estações de monitoramento do Estado de São Paulo, bem como verificou sua distribuição espacial e variação temporal. As principais conclusões do estudo apontam para uma forte dependência dos tipos de fontes dos precursores e das condições meteorológicas. 

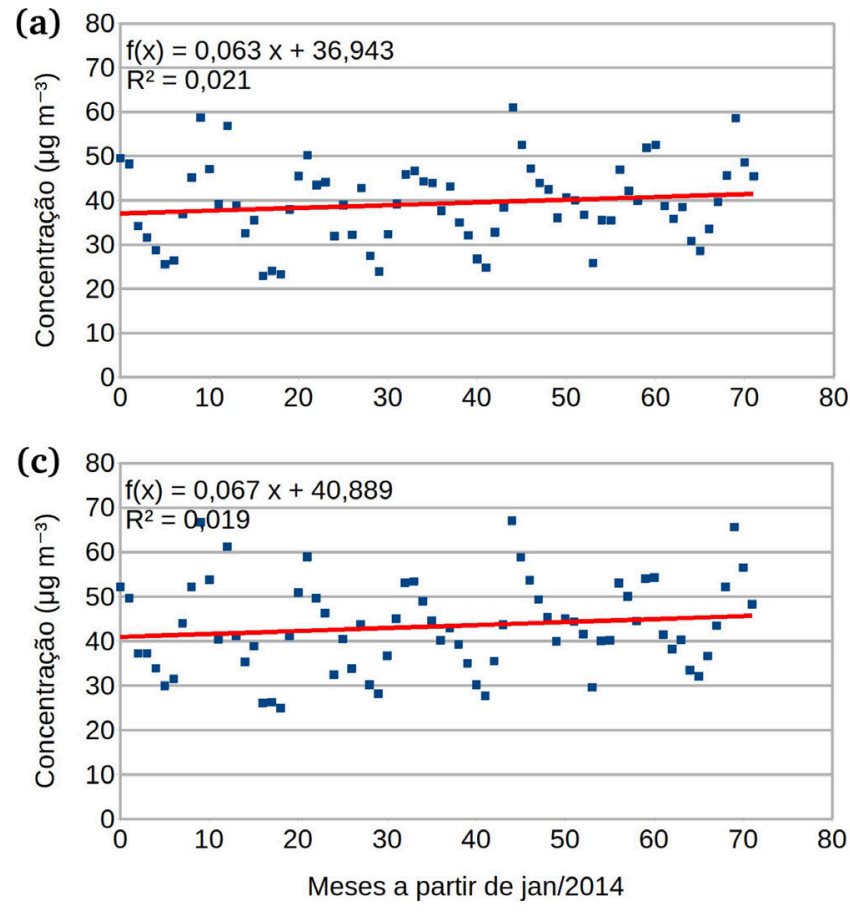

(b) 80

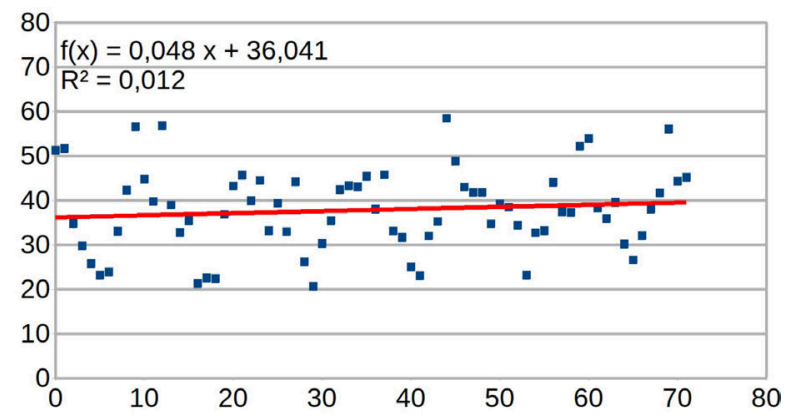

(d)

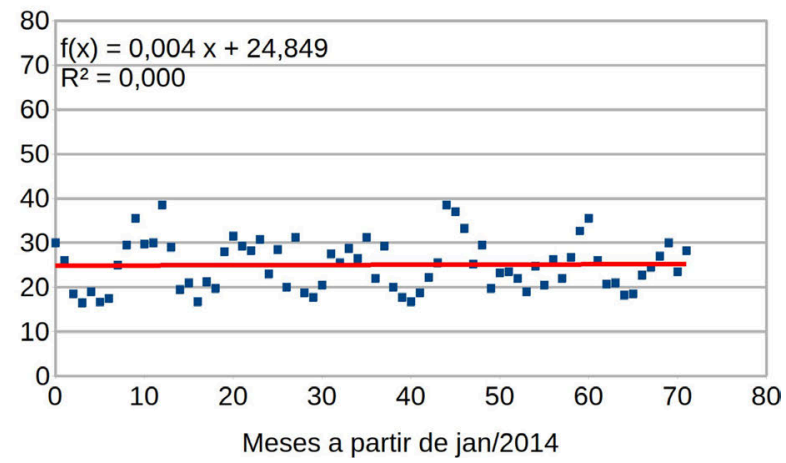

Figura 6 - Médias mensais de $\mathrm{O}_{3}$ e tendência linear considerando as estações (a) do Estado de São Paulo, (b) da RMSP, (c) do Interior e (d) da Baixada Santista. Fonte: Adaptado dos dados do sistema QUALAR.

Os meses de janeiro e outubro de 2014 e janeiro de 2015 apresentaram as situações mais críticas, com grande número de ultrapassagens no Estado de São Paulo. Destaca-se também setembro de 2017 e outubro de 2018 para a RMSP e o Interior do Estado. Já para a Baixada Santista, fevereiro de 2015 apresentou um pico de ultrapassagens que não foi importante para as outras regiões. Na RMSP também os meses de janeiro a abril e outubro de 2019 apontaram má qualidade do ar em relação ao $\mathrm{O}_{3}$ que não foi refletida na Baixada Santista e em menor grau no Interior. Comparando os anos de 2014 e 2019, vemos que os meses com mais ultrapassagens tendem a ser os mesmos: janeiro a abril e outubro. De modo geral, o verão costuma apresentar condições propícias para a formação de $\mathrm{O}_{3}$ em todo o Estado. Já a primavera é a época de maiores ultrapassagens para o Interior, enquanto a Baixada Santista não apresenta muitas ultrapassagens. A RMSP apresenta altas concentrações de $\mathrm{O}_{3}$ tanto no verão quanto na primavera.

$\mathrm{O} \mathrm{O}_{3}$ se apresenta como um poluente de difícil controle, principalmente por ser um poluente secundário, mas as autoridades públicas precisam buscar formas de controlá-lo. Uma alternativa parece ser diminuir a emissão veicular, não apenas de $\mathrm{NO}_{\mathrm{x}}$ (Diesel e gasolina), mas também de COVs (Etanol).

Os padrões utilizados no Estado são ainda conservadores se comparados aos da OMS, indicando que a percepção pública em relação ao $\mathrm{O}_{3}$ não corresponde ao real risco à saúde pública. Embora a legislação preveja uma evolução desses padrões, não há período estabelecido para que ela aconteça, passando para os limites M1. Dessa forma, urge que a tomada de decisão e o planejamento urbano considerem medidas que apontem para redução da emissão dos precursores.

\section{Referências}

ALVIM, D.S.; GATTI, L.V.; CORREA, S.M.; ORLANDO, J.P. Compostos orgânicos voláteis: Principais precursores de ozônio na cidade de São Paulo. Ciênc. Nat., v. 36, n.2, p. 434-444, 2014.

ALVIM, D.S.; GATTI, L.V.; CORRÊA, S.M.; CHIQUETTO, J.B.; ROSSATTI, C.S. et al. Main ozone-forming VOCs in the city of Sao Paulo: observations, modelling and impacts. Air Qual. Atmos. Health, v. 10, n. 4, p. 421-435, 2016.

ALVIM, D.S.; GATTI, L.V.; CORRÊA, S.M.; CHIQUETTO, J.B. Determining VOCs Reactivity for Ozone Forming Potential in the Megacity of São Paulo. Aerosol Air Qual. Res., v. 18, n. 9, p. 2460-2474, 2018.

AMANN M.; DERWENT, D.; FORSBERG, B.; HÄNNINEN, O.; HURLEY, F. et al. Health Risks of Ozone From Long-Range Transboundary Air Pollution. Copenhagen: World Health Organization Regional Office for Europe, 2008.

ANDRADE, M.F.; YNOUE, R.Y.; FREITAS, E.D.; TODESCO, E.; VARA VELA, A. et al. Air quality forecasting system for Southeastern Brazil. Front. Environ. Sci., v. 3, n. 9, 2015.

ANDRADE, M.F.; KUMAR, P.; FREITAS, E.D.; YNOUE, R.Y.; MARTINS, J. et al. Air quality in the megacity of São 
Paulo: Evolution over the last 30 years and future perspectives. Atmos. Environ., v. 159, p. 66-82, 2017.

BOIAN, C.; ANDRADE, M.F. Characterization of ozone transport among metropolitan regions. Rev. Bras. de Meteorol., v. 27, n. 2, p. 230-242, 2012.

BRAGA, A.L.; SALDIVA, P.H.N.; PEREIRA, L.A.A.; MENEZES, J.J.C.; CONCEIÇÃO, G.M.S. et al. Health effects of air pollution exposure on children and adolescents in São Paulo, Brazil. Pediatr. Pulmonol., v. 31, n. 2, p. 106-113, 2001.

BRASSEUR, G.P.; ORLANDO, J.J.; TYNDAL, G.S. Atmospheric Chemistry and Global Change. Oxford: Oxford University Press, 1999.

BRASIL. Ministério do Meio Ambiente (1986). Resolução n. 018/1986 de 6 de maio de 1986 do CONAMA - Conselho Nacional do Meio Ambiente. Dispõe sobre a criação do Programa de Controle de Poluição do Ar por Veículos Automotores - PROCONVE. Diário Oficial da República Federativa do Brasil. Brasília, DF, 17 jun. 1986. Disponível em: http://www2.mma.gov.br/port/conama/legia bre.cfm?codlegi=41. Acesso em: dez. 2020.

BRASIL. Ministério do Meio Ambiente (1990). Resolução n. 003/1990 de 28 de jun. 1990 do CONAMA - Conselho Nacional do Meio Ambiente. Estabelece padrões de qualidade do ar e dá outras providências. Diário Oficial da República Federativa do Brasil. Brasília, DF, 22 ago. 1990. Disponível em: http://www2.mma.gov.br/port/con ama/res/res90/res0390.html. Acesso em: dez. 2020.

BRITO, J.; WURM, F.; YÁÑEZ-SERRANO, A.M.; ASSUNÇÃO, J.V.; GODOY, J.M. et al. Vehicular emission ratios of VOCs in a megacity impacted by extensive ethanol use: Results of ambient measurements in São Paulo, Brazil. Environ. Sci. Technol., v. 49, n. 19, p. 11381-11387, 2015.

BRITO, J.; CARBONE, S.; SANTOS, D.A.M.; DOMINUTTI, P.; ALVES, N.O. et al. Disentangling vehicular emission impact on urban air pollution using ethanol as a tracer. Scientific Reports, v. 8, n. 10679, p. 1-10, 2018.

CARVALHO, V.S.B.; FREITAS, E.D.; MARTINS, L.D.; MARTINS, J.A.; MAZZOLI, C.R. et al. Air quality status and trends over the Metropolitan Area of São Paulo, Brazil as a result of emission control policies. Environ. Sci. Policy, v. 47, p. 68-79, 2015.

CARVALHO, V.S.B.; MARTINS, F.B.; SILVEIRA, W.W.; CAMPOS, B.; SIMÕES, J.B. Variance analysis applied to ground-level ozone concentrations in the state of São Paulo, Brazil. Braz. J. Chem. Eng., v. 37, n. 8, p. 505-513, 2020.

CETESB, 2015. Relatório de Qualidade do Ar do Estado de São Paulo 2014. Série Relatórios. Disponível em: https:// cetesb.sp.gov.br/ar/publicacoes-relatorios/. Acesso em: nov. 2020.

CETESB, 2016. Relatório de Qualidade do Ar do Estado de São Paulo 2015. Série Relatórios. Disponível em: https:// cetesb.sp.gov.br/ar/publicacoes-relatorios/. Acesso em: mar. 2021.

CETESB, 2017. Relatório de Qualidade do Ar do Estado de São Paulo 2016. Série Relatórios. Disponível em: https:// cetesb.sp.gov.br/ar/publicacoes-relatorios/. Acesso em: nov. 2020.
CETESB, 2018. Relatório de Qualidade do Ar do Estado de São Paulo 2017. Série Relatórios. Disponível em: https:// cetesb.sp.gov.br/ar/publicacoes-relatorios/. Acesso em: nov. 2020.

CETESB, 2019. Relatório de Qualidade do Ar do Estado de São Paulo 2018. Série Relatórios. Disponível em: https:// cetesb.sp.gov.br/ar/publicacoes-relatorios/. Acesso em: mar. 2021.

CETESB, 2020. Relatório de Qualidade do Ar do Estado de São Paulo 2019. Série Relatórios. Disponível em: https:// cetesb.sp.gov.br/ar/publicacoes-relatorios/. Acesso em: nov. 2020.

CHIQUeTTO, J.B. Padrões Atmosféricos Associados a Concentrações de Ozônio Troposférico na Região Metropolitana de São Paulo. Dissertação de Mestrado em Geografia Física, Universidade de São Paulo, São Paulo, 344 p., 2008.

CHIQUETTO, J.B.; YNOUE, R.Y.; CABRAL-MIRANDA, W.; SILVA, M.E.S. Concentrações de ozônio troposférico na Região Metropolitana de São Paulo e a implementação de parques urbanos: observações e modelagem. Boletim Paul. de Geogr., v. 95, p. 1-24, 2016.

CHIQUETTO, J.B.; SILVA, M.E.S.; CABRAL-MIRANDA, W.; RIBEIRO, F.N.D.; IBARRA-ESPINOSA, S.A. et al. Air quality standards and extreme ozone events in the São Paulo megacity. Sustainability, v. 11, n. 13, p. 3725, 2019.

CHRISTOFOLETTI, S.R.; MORENO, M.M.T. Sustentabilidade da mineração no polo cerâmico de Santa Gertrudes, São Paulo - Brasil. Cerâmica, v. 16, n. 3, p. 35-42, 2011.

COELHO, M.S.; DOMINUTTI, P.A.; BOIAN, C.; SANTOS, T.C.; NOGUEIRA, T. et al. Non-methane hydrocarbons in the vicinity of a petrochemical complex in the Metropolitan Area of São Paulo, Brazil. Air Qual. Atmos. Health, v. 14, n. 7, p. 967-984, 2021.

CORRÊA, S.M.; ARBILLA, G.; MARTINS, E.M.; QUITÉRIO, S.L.; GUIMARÃES, C.S. et al. Five years of formaldehyde and acetaldehyde monitoring in the Rio de Janeiro downtown area - Brazil. Atmos. Environ., v. 44, n. 19, p. 23022308, 2010.

DA CUNHA, J.M.P.; FALCÃO, C.A. (orgs.). Campinas Metropolitana: Diversidades na Virada para o Século XXI. Campinas: Librum, 2017.

D’AMELIO, M.T.S.; CAMPOS, L.C.L.; ALVIM, D. Estudo da variabilidade do monóxido de carbono atmosférico na Região Metropolitana de Campinas - SP e comparação com São Paulo - SP. Ensaios USF, v. 1, n. 1, p. 80-90, 2017.

DA SILVA, S.F. Biomonitoramento das Emissões de uma Refinaria de Petróleo em Cubatão, SP, com Indivíduos Jovens de Psidium guajava L. Paluma. Dissertação de Mestrado em Biodiversidade Vegetal e Meio Ambiente, Instituto de Botânica da Secretaria do Meio Ambiente, São Paulo, 122 p., 2012.

DOMINUTTI, P.A.; NOGUEIRA, T.; BORBON, A.; ANDRADE, M.F.; FORNARO, A. One-year of NMHCs hourly observations in São Paulo megacity: Meteorological and traffic emissions effects in a large ethanol burning context. Atmos. Environ., v. 142, p. 371-382, 2016.

DOMINUTTI, P.; NOGUEIRA, T.; FORNARO, A. BORBON, A. One decade of VOCs measurements in São Paulo mega- 
city: Composition, variability, and emission evaluation in a biofuel usage context. Sci. Total Environ., v. 738, n. 10, p. $139790,2020$.

FRANCO, D.M.P.; ANDRADE, M.F.; YNOUE, R.Y.; CHING, J. Effect of Local Climate Zone (LCZ) classification on ozone chemical transport model simulations in Sao Paulo, Brazil. Urban Clim., v. 27, p. 293-313, 2019.

FRANCISCO, A.P.; ALVIM, D.; GATTI, L.V.; PESQUERO, C.R.; ASSUNÇÃO, J.V. Ozônio troposférico e compostos orgânicos voláteis em região impactada pela agroindústria canavieira. Quím. Nova, v. 39, n. 10, p. 1177-1183, 2016.

GAVIDIA-CALDERÓN, M.; VARA-VELA, A.; CRESPO, N.M.; ANDRADE, M.F. Impact of time-dependent chemical boundary conditions on tropospheric ozone simulation with WRF-Chem: An experiment over the Metropolitan Area of São Paulo. Atmos. Environ., v. 195, p. 112-124, 2018.

GÓMEZ-PELÁEZ, L.M.; SANTOS, J.M.; ALBUQUERQUE, T.T.A.; REIS JR, N.C.; ANDREÃO, W.L. et al. Air quality status and trends over large cities in South America. Environ Sci Policy, v. 114, p. 422-435, 2020.

GROSJEAN, D.; MIGUEL, A.H.; TAVARES, T.M. Urban air pollution in Brazil: Acetaldehyde and other carbonyls. Atmos. Environ., v. 24B, n. 1, p. 101-106, 1990.

GUANABARA, A.P.S. Associação da Função Pulmonar em Estudantes do Ensino Fundamental com a Qualidade do Ar nas Cidades de Atibaia e Cubatão. Dissertação de Mestrado em Saúde Pública, Universidade de São Paulo, São Paulo, 95 p., 2011.

HOFMEISTER, V.A. Efeitos da Poluição do Ar Sobre a Função Pulmonar: Um Estudo de Coorte em Cubatão. Tese de Doutorado em Saúde Pública, Universidade de São Paulo - Departamento de Saúde Ambiental, São Paulo, 329 p., 1991.

HOGAN, D.J.; BAENINGER, R.; DA CUNHA, J.M.P.; DO CARMO, R.L. (orgs.). Migração e Ambiente nas Aglomerações Urbanas. Campinas: Núcleo de Estudos de População/UNICAMP, 2001.

HYSTAD, P.; LARKIN, A.; RANGARAJAN, S.; ALHABIB, K.F.; AVEZUM, A. et al. Associations of outdoor fine particulate air pollution and cardiovascular disease in 157436 individuals from 21 high-income, middle-income, and lowincome countries (PURE): a prospective cohort study. Lancet Planet. Health, v. 4, n. 6, p. 235-245, 2020.

IBGE. Estimativas da População Residente no Brasil e Unidades da Federação. Disponível em: https://www.ibge. gov.br/estatisticas/sociais/populacao/9103-estimativas-depopulacao.html $?=\& \mathrm{t}=$ downloads. Acesso em mar. 2021

JASINSKI, R. Análise da Associação entre Poluição Atmosférica e Internações Hospitalares por Doenças Respiratórias em Crianças, Adolescentes e Idosos na Cidade de Cubatão entre 1997 e 2004. Dissertação de Mestrado em Saúde Coletiva, Universidade Católica de Santos, Santos, 95 p., 2008.

JASINSKI, R.; PEREIRA, L.A.A.; BRAGA, A.L.F. Poluição atmosférica e internações hospitalares por doenças respiratórias em crianças e adolescentes em Cubatão, São Paulo, Brasil, entre 1997 e 2004. Cad. Saúde Pública, v. 27, n. 11, p. 2242-2252, 2011.
KLUMPP, A.; KLUMPP, G.; DOMINGUES, M. Plants as bioindicators of air pollution at the Serra do Mar near the Industrial Complex of Cubatão, Brazil. Environ. Pollut., v. 85, n. 1, p. 109-116, 1994.

KLUMPP, G.; FURLAN, C.M.; DOMINGOS, M.; KLUMPP, A. Response of stress indicators and growth parameters of Tibouchina pulchra Cogn. exposed to air and soil pollution near the industrial complex of Cubatão, Brazil. Sci. Total Environ., v. 246, n. 1, p. 79-91, 2000.

MARTINS, L.C.; LATORRE, M. do R.D.O.; BRAGA, A.; SALDIVA, P.H.N.; BRAGA, A.L.F. Relação entre poluição atmosférica e atendimentos por infecção de vias aéreas superiores no município de São Paulo: Avaliação do rodízio de veículos. Rev. Bras. Epidemiol., v. 4, n. 3, p. 221229, 2001.

MARTINS, M.C.H.; FATIGATI, F.L.; VESPÓLI, T.C.; MARTINS, L.C.; PEREIRA, L.A.A. et al. Influence of socioeconomic conditions on air pollution adverse health effects in elderly people: an analysis of six regions in São Paulo, Brazil. Epidemiol. Community Health, v. 58, n. 1, p. 4146, 2004.

MARTINS, L.D.; ANDRADE, M.F. Ozone formation potentials of volatile organic compounds and ozone sensitivity to their emission in the megacity of São Paulo, Brazil. Water Air Soil Pollut., v. 195, n. 1, p. 201-213, 2008.

MARTINS, E.M.; NUNES, A.C.L.; CORRÊA, S.M. Understanding Ozone Concentrations During Weekdays and Weekends in the Urban Area of the City of Rio de Janeiro. J. Braz. Chem. Soc., v. 26, n. 10, p. 1967-1975, 2015.

MARTINS, L.D.; VIDOTTO, L.H.B.; ALMEIDA, D.S.; SQUIZATTO, R.; MOREIRA, C.A.B. et al. The role of mediumsized cities for global tropospheric ozone levels. Energy Procedia, v. 95, p. 265-271, 2016.

MASSAMBANI, O.; ANDRADE, M.F. Seasonal behavior of tropospheric ozone in the São Paulo (Brazil) Metropolitan Area. Atmos. Environ., v. 28, n. 19, p. 3165-3169, 1994.

NARDOCCI, A.C.; FREITAS, C. U.; DE LEON, A.C.M.P.; JUNGER, W.L.; GOUVEIA, N.C. Poluição do ar e doenças respiratórias e cardiovasculares: estudo de séries temporais em Cubatão, São Paulo, Brasil. Cad. Saúde Pública, v. 29, n. 9, p. 1867-1876, 2013.

NOGUEIRA, T.; DOMINUTTI, P.A.; CARVALHO, L.R.F.; FORNARO, A.; ANDRADE, M.F. Formaldehyde and acetaldehyde measurements in urban atmosphere impacted by the use of ethanol biofuel: Metropolitan area of São Paulo (MASP), 2012-2013. Fuel, v. 134, p. 505-513, 2014.

NOGUEIRA, T.; DOMINUTTI, P.; FORNARO, A.; ANDRADE, M.F. Seasonal trends of formaldehyde and acetaldehyde in the megacity of São Paulo. Atmosphere, v. 8, n. 144, p. 1-18, 2017.

ORLANDO, J.P.; ALVIM, D.S.; YAMAZAKI, A.; CORREAA, S.M.; GATTI, L.V. Ozone precursors for the São Paulo Metropolitan Area. Sci. Total Environ., v. 408, n. 7, p. 1612-1620, 2010.

PROCLIMA. Gases do Efeito Estufa e Fontes de Emissão. Cetesb: São Paulo, 2021. Disponível em: https://cetesb.sp. gov.br/proclima/gases-do-efeito-estufa/. Acesso em: jan. 2021. 
SALVO, A.; GEIGER, F. Reduction in local ozone levels in urban São Paulo due to a shift from ethanol to gasoline use. Nat. Geosci., v. 7, n. 6, p. 450-458, 2014.

SALVO, A.; WANG, Y. Ethanol-blended gasoline policy and ozone pollution in São Paulo. J. Assoc. Environ. Resour. Econ., v. 4, n. 3, p. 731-794, 2017.

SÁNCHEZ-CCOYLLO, O.R.; YNOUE, R.Y.; MARTINS, L.D.; ANDRADE, M.F. Impacts of ozone precursor limitation and meteorological variables on ozone concentration in São Paulo, Brazil. Atmos. Environ., v. 40, n. 2, p. 552-562, 2006a.

SÁNCHEZ-CCOYLLO, O.R.; SILVA-DIAS, P.L.; ANDRADE, M.F.; FREITAS, S.R. Determination of O3-, CO- and PM10-transport in the metropolitan area of São Paulo, Brazil through synoptic-scale analysis of back trajectories. Meteorol. Atmos. Phys., v. 92, n. 1, p. 83-93, 2006 b.

SANTOLAYA, C.; OLIVEIRA, M.C.Q.D.; RIZZO, L.V.; MIRAGLIA, S.G.E.K. Contribuição de fatores químicos e meteorológicos para a formação de ozônio troposférico em São Paulo. Rev. Bras. de Ciên. Ambient., n. 54, p. 90-104, 2019.

SÃO PAULO. (2013). Decreto 59.113, 23 de abril de 2013. Disponível em https://www.al.sp.gov.br/repositorio/legislacao/ decreto/2013/decreto-59113-23.04.2013.html. Acesso em jan. 2021.

SCHWARTZ, J. Air pollution and children's health. Pediatrics, v. 113, n. 4, p. 1037-1043, 2004.

SCHUCH, D.; FREITAS, E.D.; IBARRA-ESPINOSA, S.; MARTINS, L.D.; CARVALHO, V.S.B. et al. A two decades study on ozone variability and trend over the main urban areas of the São Paulo state, Brazil. Environ. Sci. Pollut. Res., v. 26, n. 31, p. 31699-31716, 2019.

SEINFELD, J.H., 1989. Urban air pollution: State of the science. Science, v. 243, n. 4892, p. 745-752.

SHARKEY, T.D.; LORETO, F. Water stress, temperature, and light effects on the capacity for isoprene emission and photosynthesis of kudzu leaves. Oecologia, v. 95, n. 3, p. 328333, 1993.

SQUIZZATO, R.; NOGUEIRA, T.; MARTINS, L.D.; MARTINS, J.A.; ASTOLFO, R. et al. Beyond megacities: track- ing air pollution from urban areas and biomass burning in Brazil. NPJ Clim. Atmos. Sci., v. 4, e17, 2021.

TARGINO, A.C.; HARRISON, R.M.; KRECL, P.; GLANTZ, C. H.L.; BEDDOWS, D. Surface ozone climatology of South Eastern Brazil and the impact of biomass burning events. J. Environ. Manag., v. 252, n. 4, p. 109645, 2019.

TRESMONDI, A.C.L.; TOMAZ, E. Air pollution and the influence of sources on Paulínia (Brazil) and surroundings. Int J Environ Pollut., v. 22, n. 4, p. 490-506, 2004.

UEDA, A.C.; TOMAZ, E. Inventário de emissão de fontes veiculares da Região Metropolitana de Campinas, São Paulo. Quím. Nova, v. 34, n. 9, p. 1496-1500, 2011.

WANG, T.; XUE, L.; BRIMBLECOMBE, P.; LAM, Y.F.; LI, L.; ZHANG, L. Ozone pollution in China: A review of concentrations, meteorological influences, chemical precursors, and effects. Sci. Total Environ., v. 575, p. 15821596, 2017.

WEITKAMP, C.; GOERS, U.B.; GLAUER, J.; KOHLER, S. Laser Remote Sensing of Sulfur Dioxide, Nitrogen Dioxide, Toluene, Ozone, and Dust in the Industrial Area of Cubatão (Brazil). In: Ansmann A., Neuber R., Rairoux P., Wandinger U. (eds) Advances in Atmospheric Remote Sensing with Lidar. Springer: Berlin, Heidelberg, 1997.

\section{Internet Resources}

Boletim Climatológico Anual da Estação Meteorológica do IAG/ USP/ Seção Técnica de Serviços Meteorológicos - Instituto de Astronomia, Geofísica e Ciências Atmosféricas da Universidade de São Paulo - São Paulo: IAG/USP, 2021. Disponível em: http://www.estacao.iag.usp.br/boletim.php.

CETESB. QUALAR: Sistema de Informações da Qualidade do Ar. São Paulo, 2021. Base de dados eletrônicos (portal). Tema: Qualidade do Ar. Disponível em: http://cetesb.sp. gov.br/ar/qualar/.

License information: This is an open-access article distributed under the terms of the Creative Commons Attribution License (type CC-BY), which permits unrestricted use, distribution and reproduction in any medium, provided the original article is properly cited. 